\title{
Asymmetric michael adducts as key building blocks for synthesis of bioactive molecules
}

\begin{abstract}
A over view of the synthesis of enantiopure bioactive molecules such as, Nepetalactol, isofebrifugine, (R)-Montelukast, phosphanylamino acids and (S)-Pregabalin are efficiently synthesized from common intermediate as Michael adducts by various types of Michael addition reaction and further Michael adduct are potentially leading towards the synthesis of varieties bioactive molecules.
\end{abstract}

Keywords: michael addition, thio michael addition, aza-michael addition, oxomichael, phosphate michael addition

\author{
Volume I Issue 5 - 2017 \\ Manojkumar U Chopade,' Anil U Chopade, ${ }^{2}$ \\ Aadil A Momin ${ }^{3}$ \\ 'Department of Chemistry, Sant Dnyaneshwar Mahavidyalaya, \\ India \\ ${ }^{2}$ Department of Chemistry, Dahiwadi College, Dahiwadi, Rayat \\ Shikshan Sansthan, Satara, Shivaji University Kolhapur, India \\ ${ }^{3}$ JAT Arts, Science and Commerce College (for women) \\ Malegaon, India
}

\section{Correspondence: Manojkumar U Chopade, Sant Dnyaneshwar Mahavidyalaya, Department of Chemistry, Soegaon, Aurangabad-43 I I 20, India, Tel +9 I-2438-234395, Email chopademanojkumar@gmail.com}

Received: June 18, 2017| Published: October 02, 2017

\section{Introduction}

Michael reaction involves the addition of a nucleophiles (also known as donor, which can be $\mathrm{C}$ and heteroatom i.e. $\mathrm{O}, \mathrm{S}, \mathrm{P}, \mathrm{N}$ ) on alkenes, or alkynes attached to electron withdrawing groups (also known as acceptor). ${ }^{1}$ The conjugate addition of carbon nucleophiles to $\alpha, \beta$ unsaturated compounds is an important $\mathrm{C}$-C-bond formation reaction. ${ }^{2}$ This transformation shows a broad scope due to the large variety of acceptors $(\alpha, \beta$-unsaturated aldehydes, esters, ketones, phosphonates, sulfones, cyanoester thioesters and nitrostyrenes) and nucleophiles (organometallic reagents, Michael donors, other carbanions). ${ }^{3}$

The carbon centered nucleophilic addition may take place in enantioselective or non-enantioselective manner. As result the increase the demand for optically active compounds in the recent years, tremendous progress has been made in the field of asymmetric version of reaction, providing the Michael adduct having high enantiomeric purity. The asymmetric Michael reaction could be categorized in three categories:

a. Asymmetric addition of prochiral donor compounds to acceptor;

b. Asymmetric addition of a donor to a prochiral acceptor compounds;

c. Asymmetric addition of enantioselective as well as distereoselective addition of prochiral donor to prochiral acceptor in Figure 1.

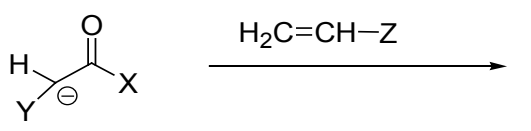<smiles>[Z]CC[C@H]([Y])C([X])=O</smiles>

and/or<smiles>[Z]CC[C@H]([Y])C([X])=O</smiles>

Prochiral donor<smiles>[R]C=CC([X])=O</smiles><smiles></smiles>

Prochiral Acceptor<smiles>[R]C=CC([R2])C[18O]</smiles>

Prochiral donor Prochiral Acceptor

Figure I Asymmetric michael addition reaction. 
Enantioselective synthesis, also called chiral synthesis or asymmetric synthesis, in the form of many of the building blocks in biological systems, such as sugars, lipids, nucleotides and amino acids are the major biochemical compounds essential for normal functioning of the human organism. ${ }^{4}$ The Michael adducts can bear a single substituent or dual substituents adjacent to the carbonyl. The Michael adducts can be efficiently converted to cyclically constrained protected compounds, which are essential for systematic conformational studies of cyclic compound. Despite that now a day's variety methods for the asymmetric synthesis of sulphur ${ }^{5}$ and phosphates derivatives. ${ }^{6}$

In the recent years, Michael addition is one of the powerful and versatile methods for the construction of $\mathrm{C}-\mathrm{C}, \mathrm{C}-\mathrm{N}, \mathrm{C}-\mathrm{S}, \mathrm{C}-\mathrm{O}$ bond containing enantiomerically pure compounds and has found wide application in the field of both novelty and high selectivity attained by Michael adducts. ${ }^{7}$ Enantioselective synthesis of natural product and drug has gained significant importance because of their interesting pharmacological applications as biological activities as well potent insecticidal properties. ${ }^{8}$

The objective of this review paper is to discuss the asymmetric conjugate addition associated with the various Michael reactions i.e. Michael addition, Thio Michael addition, Aza-Michael addition, Oxo-Michael and Phosphate Michael addition reaction to produce various significant intermediate in the field of organic synthesis, and shown its relevance in biological activities. Further advantages of this methodology are connected to economy, simplicity and inculcate a new catalyst for various organic transformations. ${ }^{9}$

\section{Types of michael additions}

\section{Oxo michael addition ${ }^{10}$}

Stereoselective synthesis of nepetalactol has been achieved by Oxo-Michael addition is key step. 10-hydroxygeranial 1 is oxidized to 10 -Oxogeranial 2 by $\mathrm{SeO}_{2}$ in DCM. The 10-Oxogeranial 2 which on Iridoid synthase by NADPH to form enol/enolate intermediate 3 , then intermediate 3 on Oxo-Michael addition and terpene cyclization to form open form of iridodial 4 finally tautomerism afford target molecule 5a i.e. Nepetalactol (Figure 2).

\section{Aza-michael reaction"}

Isofebrifugine was synthesized from starting material D-mannitol 6. D-mannitol is converted to Michael acceptor intermediate 7. It was then intermediate 7 on intramolecular cyclization under the azaMichael reaction to form desirable protected cyclic unit 8 of target molecule. The intermediate 8 on bromination followed by coupling with 10 to get protected intermediate 11 . The protected intermediate 11 on deprotection using $6 \mathrm{~N} \mathrm{HCl}$ in reflux condition to form febrifugine, febrifugine 12 treated with acidic condition to get desired target molecule i.e. Isofebrifugine 13 (Figure 3) .

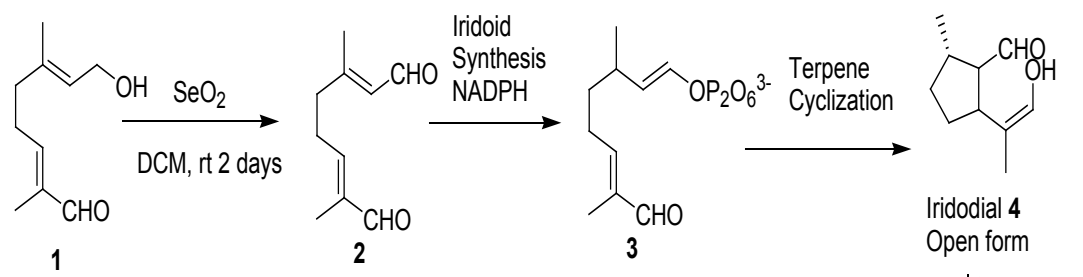

Figure 2 Oxo michael addition.

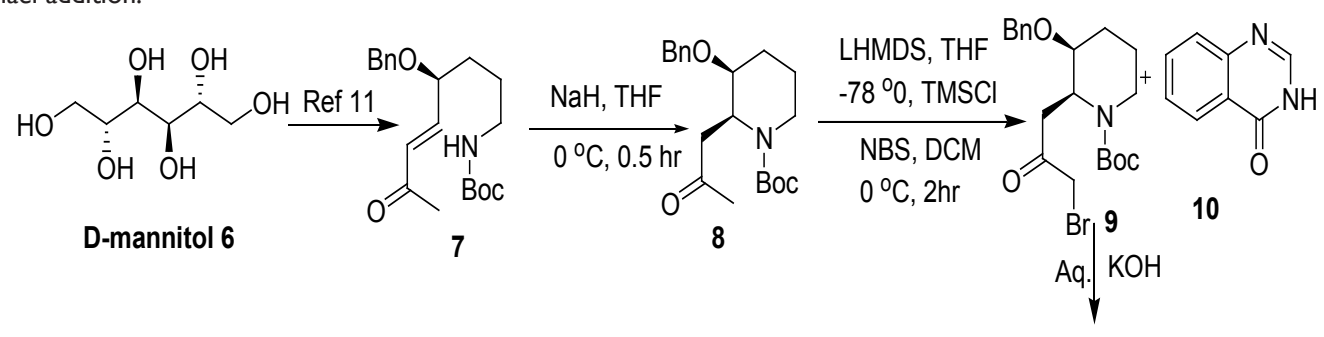<smiles>O=c1c2ccccc2ncn1CC1(O)C[C@H]2NCCCC2O1</smiles>

Isofebrifugine 13<smiles>CC(C)[C@H](C)Cc1ccc2ncn(CC(=O)C[C@H]3NCCC[C@H]3O)c(=O)c2c1</smiles>

Febrifugine 12<smiles></smiles>

Figure 3 Aza-Michael reaction. 


\section{Thio michael addition reaction ${ }^{12}$}

The total synthesis of (R)-Montelukast 19 involves asymmetric addition of thiols to $\alpha, \beta$-unsaturated ketones is a key step. Michael addition of 1-(mercaptomethyl)cyclopropyl]acetic acid 15 to substituted chalcone 14 to afford Michael adduct 16, which on condensation with tosylhydrazone followed by reduction with sodium borohydride to obtain sulphide 18. Finally, sulphide 18 on Grignard reaction by addition of methyl magnesium bromide on ester furnished (R)-Montelukast 19. The sulfa-Michael addition reaction on substituted chalcone to form $\beta$-thioketones in excellent yield with high enantioselectivity and experimental that probe to the scope of aliphatic and aromatic thiols (Figure 4).

\section{Phosphate michael addition reaction ${ }^{13}$}

Enantioselective Michael addition of dialkyl phosphate to provide $\beta$-nitro phosphate followed by reduction of nitro group would affords

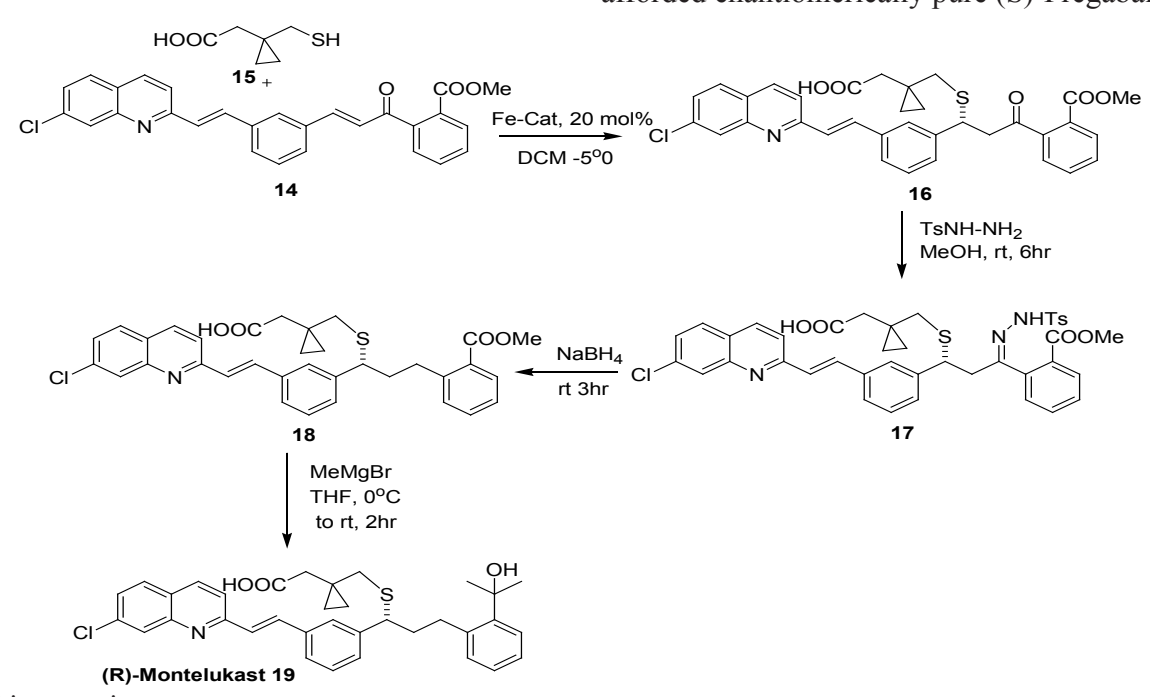

Figure 4 Thio michael addition reaction.<smiles>O=[N+]([O-])C=Cc1ccccc1</smiles><smiles>CN(C)C1CCCCCC1NC(=O)C(=O)Nc1ccc(C(F)(F)F)cc1C(F)(F)F</smiles>

Sqaraamide 22

Figure 5 Phosphate michael addition reaction.<smiles></smiles>

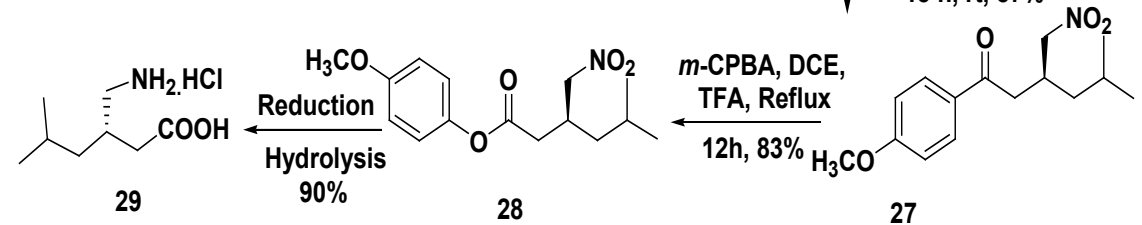

Figure 6 Michael addition reaction. 


\section{Conclusion}

In summary, the asymmetric induction can originate by all types of asymmetric Michael addition reaction to construct the enantiopure key intermediate unit of drug molecule, the importance of key intermediate compounds tremendous progress has been made in the recent years. The class of all enantioselective Michael addition has contributed immensely in stereoselective synthetic methods and valuable synthesized building blocks bearing varieties of biological activities and improved novel asymmetric Michael reactions are applicable for their future in asymmetric synthetic world.

\section{Acknowledgements}

Manojkumar U Chopade is thankful to Dr. Ganesh M Agnihotri Principal, Dr. Shirish S Pawar (Vice Principal) and Dr. Raosaheb K Barote (Vice Principal) of Sant Dnyaneshwar Mahavidyalaya Soegaon, Aurangabad, for financial support and infrastructural facility and also thankful to CSIR, New Delhi and UGC.

\section{Conflict of interest}

The author declares no conflict of interest.

\section{References}

1. Zeng X. Recent Advances in Catalytic Sequential Reactions Involving Hydroelement Addition to Carbon-Carbon Multiple Bonds. Chem Rev. 2013;113(8):6864-6900.

2. Chopade MU, Chopade AU. $\mathrm{NiCl}_{2}:$ Sparteine Catalysed Enantioselective Michael Addition of Diethyl Malonate on $\beta$-Nitrostyrene: Concise Synthesis of (R)-Rolipram. Journal of Chemistry and Chemical Sciences. 2015;5(11):585-590.

3. Vicario JL, Dolores B, Luisa C, et al. Organocatalytic Enantioselective Conjugate Addition Reactions: A Powerful Tool for the Stereocontrolled Synthesis of Complex Molecules. Royal Society of Chemistry. 2011:117.
4. Krzyściak W. Activity of selected aromatic amino acids in biological systems. Acta Biochim Pol. 2011;58(4):461-466.

5. Fenga M, Tanga B, Liangb SH, et al. Sulfur Containing Scaffolds in Drugs: Synthesis and Application in Medicinal Chemistry. Curr Top Med Chem. 2016;16(11):1200-1216.

6. Krithika R, Srivastava PL, Rani B, et al. Characterization of 10-Hydroxygeraniol Dehydrogenase from Catharanthus roseus Reveals Cascaded Enzymatic Activity in Iridoid Biosynthesis. Sci Rep. 2015;5:8258.

7. Singh GS, Yeboah EMO. Recent applications of Cinchona alkaloidbased catalysts in asymmetric addition reactions. Reports in Organic Chemistry. 2016;6:47-75.

8. Dias DA, Urban S, Roessner U. A Historical Overview of Natural Products in Drug Discovery. Metabolites. 2012;2(2):303-336.

9. Matthew JW, Carin CCJ, Andy MN, et al. Enantioselective Organocatalysis. Drug Discovery Today. 2007;12(1-2):8-27.

10. Lindner S, Geu-Flores F, Bräse S, et al. Conversion of Substrate Analogs Suggests a Michael Cyclization in Iridoid Biosynthesis. Chem Biol. 2014;21(11):1452-1456.

11. Sudhakar N, Srinivasulu G, Rao GS, et al. The formal synthesis of isofebrifugine using stereoselective intramolecular Michael addition. Tetrahedron Asymmetry. 2008;19(18):2153-5158.

12. White JD, Shaw S. Iron catalyzed enantioselective sulfa-Michael addition: a four-step synthesis of the anti-asthma agent Montelukast. Chem Sci. 2014;5(6):2200-2204

13. Zhu Y, Malerich JP, Rawal VH. Squaramide-Catalysed Enantioselective Michael Addition of Diphenyl phosphite to Nitroalkenes. Angew Chem Int Ed. 2010;49(1):153-156.

14. Chopade MU, Chopade AU, Nikalje MD. Enantioselective Michael reaction of Nitromethane on Chalcones using $\mathrm{Cu}(\mathrm{acac})_{2}$ : Sparteine as a Chiral ligand: Concise synthesis of anticonvulsant drug (S)-Pregabalin. Adv Org Chem Lett. 2016;3(1):4-7. 